\title{
Influence of Controller's Parameters on Static Bifurcation of Magnetic-Liquid Double Suspension Bearing
}

\author{
Jianhua Zhao ${ }^{1,2, *}$, Hanwen Zhang ${ }^{1, *}$, Bo Qin ${ }^{1, *}$, Yongqiang Wang ${ }^{1, *}$, Xiaochen Wu ${ }^{1, *}$, Fang Han ${ }^{1, *}$ \\ and Guojun $\mathrm{Du}^{2, *}$
}

check for

updates

Citation: Zhao, J.; Zhang, H.; Qin, B.; Wang, Y.; Wu, X.; Han, F.; Du, G. Influence of Controller's Parameters on Static Bifurcation of Magnetic-Liquid Double Suspension Bearing. Energies 2021, 14, 8241. https://doi.org/10.3390/en14248241

Academic Editors: Davide Astolfi and Teuvo Suntio

Received: 29 October 2021

Accepted: 1 December 2021

Published: 7 December 2021

Publisher's Note: MDPI stays neutral with regard to jurisdictional claims in published maps and institutional affiliations.

Copyright: (c) 2021 by the authors. Licensee MDPI, Basel, Switzerland. This article is an open access article distributed under the terms and conditions of the Creative Commons Attribution (CC BY) license (https:// creativecommons.org/licenses/by/ $4.0 /)$.
1 Fluid Power Transmission and Control Laboratory, Yanshan University, Qinhuangdao 066004, China

2 College of Civil Engineering and Mechanics, Yanshan University, Qinhuangdao 066004, China

* Correspondence: zhaojianhua@ysu.edu.cn (J.Z.); zhanghanwengw@163.com (H.Z.); qin000bo@163.com (B.Q.); wang1245128709@163.com (Y.W.); wuxiaochen8888@163.com (X.W.); hanfang7291@163.com (F.H.); dugj2002@ysu.edu.cn (G.D.)

\begin{abstract}
Magnetic-Liquid Double Suspension Bearing (MLDSB) is composed of an electromagnetic supporting and a hydrostatic supporting system. Due to greater supporting capacity and static stiffness, it is appropriate for occasions of middle speed, overloading, and frequent starting. Because of the complicated structure of the supporting system, the probability and degree of static bifurcation of MLDSB can be increased by the coupling of hydrostatic force and electromagnetism force, and then the supporting capacity and operation stability are reduced. As the key part of MLDSB, the controller makes an important impact on its supporting capacity, operation stability, and reliability. Firstly, the mathematical model of MLDSB is established in the paper. Secondly, the static bifurcation point of MLDSB is determined, and the influence of parameters of the controller on singular point characteristics is analyzed. Finally, the influence of parameters of the controller on phase trajectories and basin of attraction is analyzed. The result showed that the pitchfork bifurcation will occur as proportional feedback coefficient $K_{p}$ increases, and the static bifurcation point is $K_{p}=-60.55$. When $K_{p}<-60.55$, the supporting system only has one stable node $(0,0)$. When $K_{p}>-60.55$, the supporting system has one unstable saddle $(0,0)$ and two stable non-null focuses or nodes. The shape of the basin of attraction changed greatly as $K_{p}$ increases from -60.55 to 30 , while the outline of the basin of attraction is basically fixed as $K_{p}$ increases from 30 to 80 . Differential feedback coefficient $K_{d}$ has no effect on the static bifurcation of MLDSB. The rotor phase trajectory obtained from theoretical simulation and experimental tests are basically consistent, and the error is due to the leakage and damping effect of the hydrostatic system within the allowable range of the engineering. The research in the paper can provide theoretical reference for static bifurcation analysis of MLDSB.
\end{abstract}

Keywords: magnetic-liquid double suspension bearing; static bifurcation; phase path; attraction basin; parameter controller

\section{Introduction}

Hydrostatic bearing is introduced into electromagnetic bearing to form MagneticLiquid Double Suspension Bearing (MLDSB). It has the advantage of non-mechanical contact, high supporting capacity and stiffness, and therefore, the operation stability and service life of electromagnetic bearing can be efficiently improved. Thus, it is suitable for deep-sea exploration, hydropower generation and other domains, especially medium-low speed, heavy load, and frequent starting occasion [1].

MLDSB is composed of an electromagnetic bearing and a hydrostatic bearing as shown in Figures 1-3 [2], and it can take full advantage of electromagnetic and hydrostatic bearing systems. The hydrostatic force can be added into the MLDSB on the premise of not affecting the electromagnetic force. 


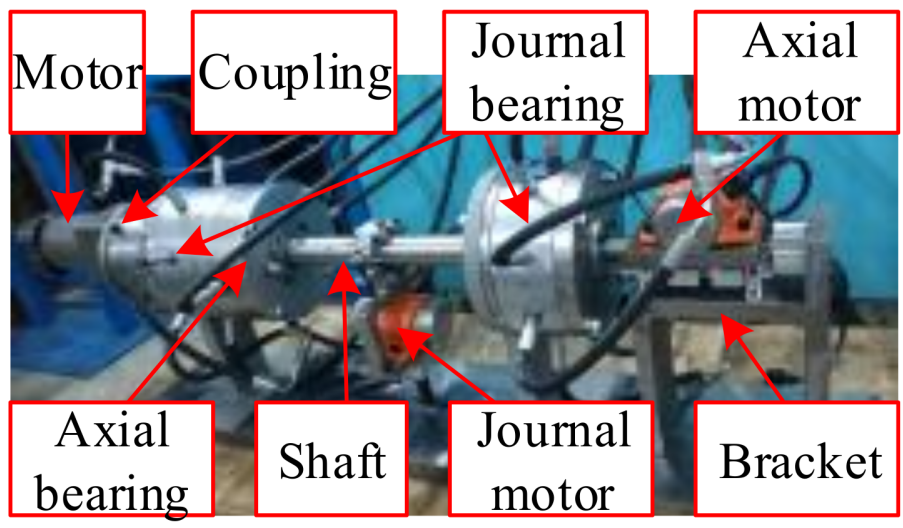

Figure 1. Semi-isometric view of MLDSB.

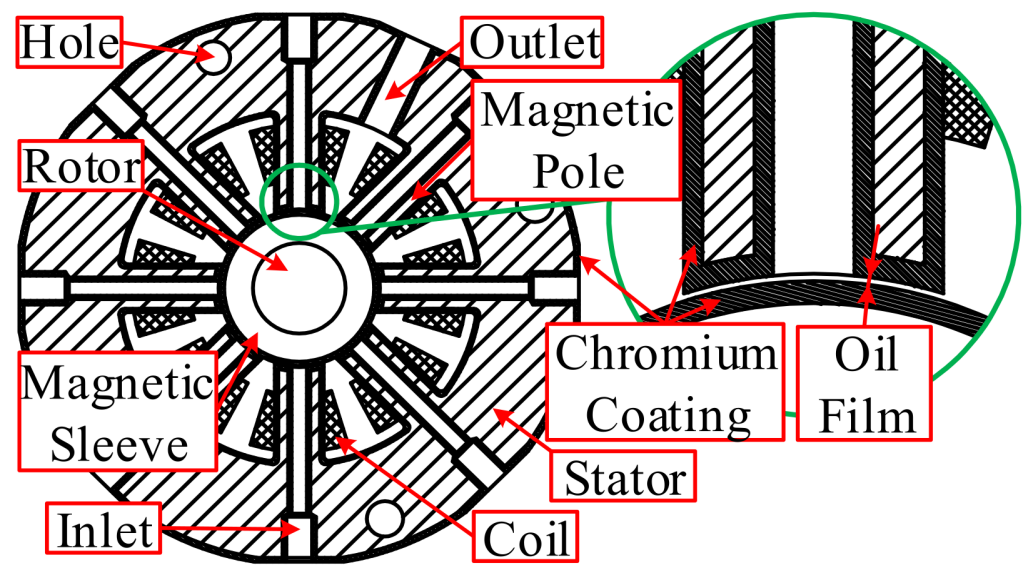

Figure 2. Sectional view of radial unit of MLDSB.

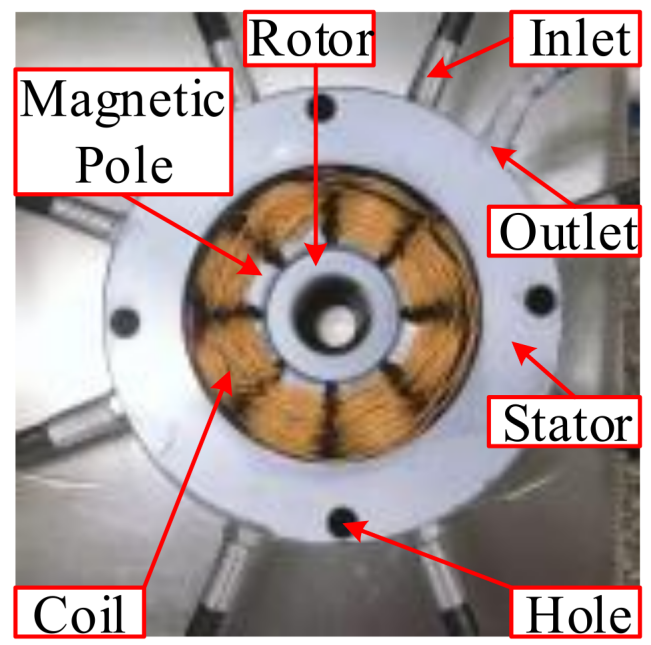

Figure 3. Photo of radial unit of MLDSB.

The control principle of MLDSB is shown in Figure 4. The probability and degree of static bifurcation are improved by coupling and interfering with the nonlinear hydrostatic systems and electromagnetic system, which sharply decrease the reliability and operation stability of MLDSB [2]. 


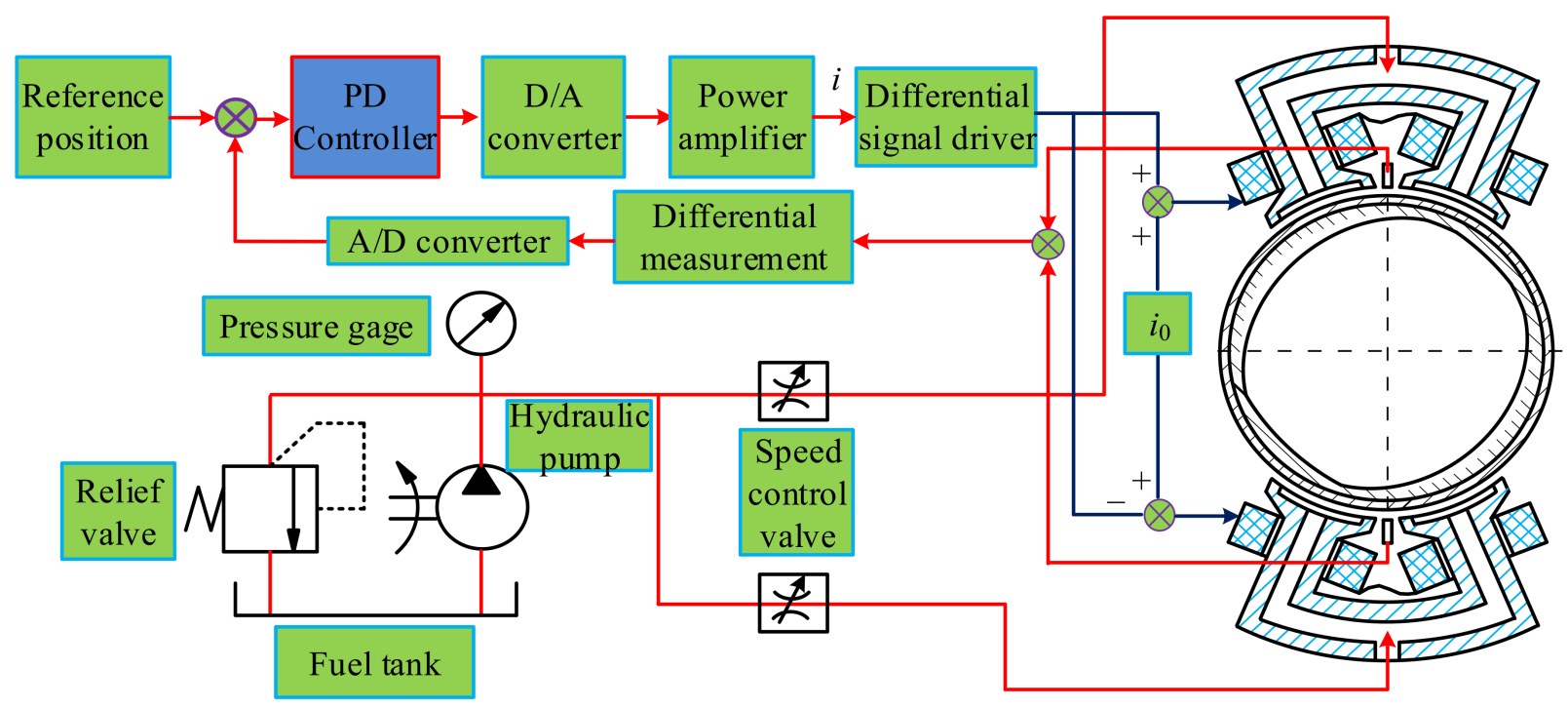

Figure 4. Single DOF support regulation principle of MLDSB.

The controller has an important impact on supporting capacity, operation stability, and reliability of MLDSB [3].

Many scholars have studied the effect of the controller on electromagnetic bearing and have achieved fruitful results.

HE [4] simulated the PID controller of a factual magnetic rotor-bearings system by Matlab and arrived at the dynamic performance curves of some parameter fields. The results indicate that the parameters of the controller can affect the performance of the magnetic rotor-bearings system greatly.

CHEN [5] constructed the minimum augmented system model by selecting appropriate auxiliary equations and explored the influence of couplings between parameters on the stability of digital hydraulic actuation systems, which improved the robustness and computational efficiency of two-parameter bifurcation analysis by the numerical continuation method and obtained the Hopf bifurcation boundary of the system in the two-dimensional parameter plane and verified it.

YANG [6] investigated the nonlinear vibration of a mono-degree of freedom rotor supported by the AMBs and observed the typical nonlinear phenomena with the altering of the PID controller's parameters, and then analyzed the resonance curve in the area of nature frequency.

JI [7-9] provides the background information on the analysis method for the nonlinear dynamics of magnetic bearing rotors and discusses the present situation and the possible directions for future research on the nonlinear dynamics of magnetic bearing systems.

CHEN [10] aimed to study the influence of time delay of the maglev train controller on suspension stability and established a single-degree-of-freedom model based on doubleloop feedback, and quantitatively gave the critical value of Hopf bifurcation in the system. Finally, the correctness of the theory is verified by experiments.

JI [11-13] studied the influence of time delay in PID controllers on the linear stability of simple electromechanical systems by analyzing characteristic transcendental equations. It was found that when the time delay exceeds a certain critical value, the trivial fixed point of the system will lose its stability through Hopf bifurcation.

WU [14] designed the variable parameter PID control algorithm for the remote monitoring system and simulated the motion by using the designed PID algorithm. The numerical examples show that the designed PID algorithm greatly increases the stability of the nonlinear periodic motions and ensures the stable harmonic motions of the system.

LAN [15] established the dynamic model of permanent magnet motor rotor, and based on the transition process from Hopf bifurcation to chaos, analyzed the influence of system 
parameters on the behavior of rub-impact systems and improved the safety and stability at high speed.

In conclusion, the research achievements of scholars at home and abroad are mainly focused on the influence of the controller on electromagnetic bearings. However, research on the influence on the static bifurcation of MLDSB has not yet been reported.

Due to its strong nonlinear properties, static bifurcation is easy to occur in MLDSB. Therefore, the mathematical model of MLDSB is established in the paper, and the influence of parameters of the controller on the static bifurcation point, singular point characteristics, phase trajectories, and basin of attraction are analyzed.

\section{Mathematical Model of the Single-DOF Supporting System of MLDSB}

\subsection{Structure of MLDSB}

There are eight magnetic poles distributed along the circumference in MLDSB. Two adjacent anisotropic magnetic poles are paired. In initial conditions, the electromagnetic force of each pole and the hydrostatic force of the supporting cavity are equal. Therefore, electromagnetic force and hydrostatic force which are produced by a pair of magnetic poles are equal, it is named supporting unit.

The vertical single-DOF supporting system is taken as the research object, and it is mainly composed of an upper supporting unit, a lower supporting unit, and a rotor, as shown in Figure 5.

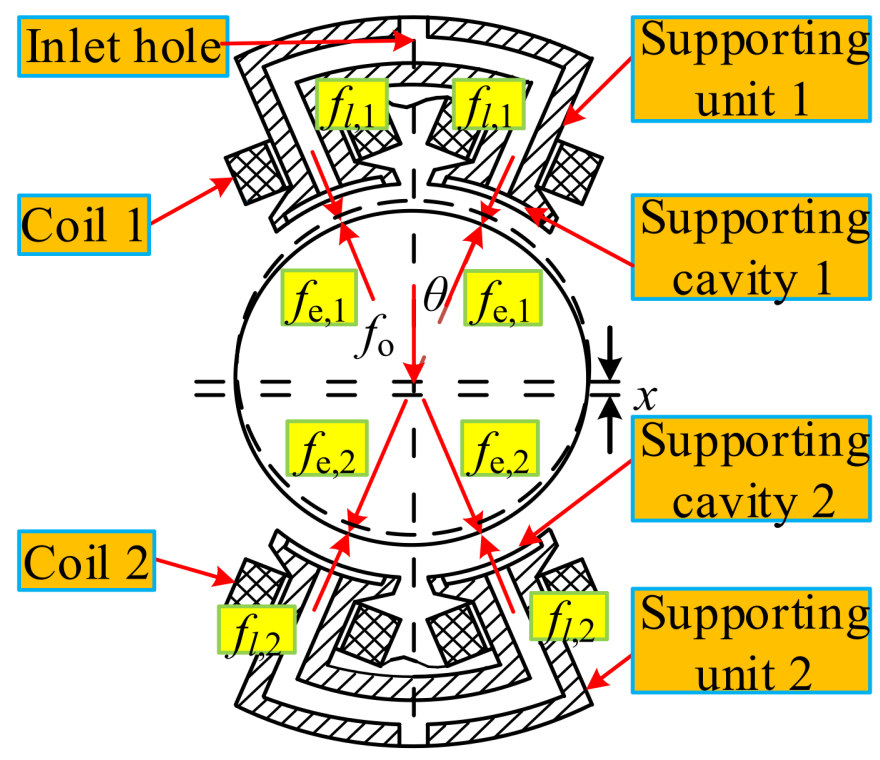

Figure 5. Force diagram of single DOF MLDSB.

In order to study the supporting characteristics, assumptions can be made as follows [16,17]:

(1) The flow state of liquid is laminar, and the inertia force can be ignored.

(2) Due to the low pressure, the viscous-pressure characteristics of liquid can be ignored.

(3) Leakage magnetic flux of the winding can be ignored.

(4) Magnetoresistance of iron core and rotor can be ignored, and then the magnetic potential only acts on the air gap.

(5) The influence of magnetic material's hysteresis and eddy current can be ignored.

(6) The support surface is rigid.

(7) The gravity of rotor can be ignored. 


\subsection{Non-Linear Equation of the Single-DOF Supporting System}

According to literature [18], the equilibrium equation of rotor can be expressed as follows:

$$
\sum_{i=1}^{2} f_{e} \frac{\left[1+(-1)^{i} \frac{150\left(K_{p} x+K_{d}\right)}{i_{0}}\right]^{2}}{\left[1+(-1)^{i+1} \frac{x \cos \theta}{h_{0}}\right]^{2}}-\sum_{i=1}^{2} f_{h} \frac{\left[1+(-1)^{i} \frac{(A-2 a)(B-2 b) \cos \theta}{q_{0}}\right]}{\left[1+(-1)^{i+1} \frac{x \cos \theta}{h_{0}}\right]^{3}}=-m \ddot{x}
$$

where $f_{e}:$

$$
f_{e}=\mu_{0} N^{2} A_{1} i_{0}^{2} \cos \theta / 2 h_{0}^{2}
$$

$f_{h}$ :

$$
f_{h}=2 \mu q_{0} A_{e} \cos \theta / \bar{B} h_{0}^{3}
$$

$\bar{B}$ :

$$
\bar{B}=(A-a) /(6 b)+(B-b) /(6 a)
$$

$A_{e}:$

$$
A_{e}=(A-B)(B-b)
$$

Parameters of the mathematical model of MLDSB are shown in Table 1.

Table 1. Parameters of mathematical model of MLDSB.

\begin{tabular}{ccc}
\hline Parameter & Name & Unit \\
\hline$\mu_{0}$ & Permeability of air & $\mathrm{H} / \mathrm{m}$ \\
$N$ & Number of coils & dimensionless \\
$A_{1}$ & Area of magnetic pole & $\mathrm{m}^{2}$ \\
$\theta$ & Angle between supporting cavity and axis line & $\circ$ \\
$i_{0}$ & Initial and control current of coil & $\mathrm{A}$ \\
$i_{c}$ & Initial and control current of coil & $\mathrm{A}$ \\
$K_{p}$ & Controller parameters & dimensionless \\
$K_{d}$ & Controller parameters & dimensionless \\
$x$ & Displacement of rotor & $\mathrm{m}$ \\
$h_{0}$ & Initial film thickness & $\mathrm{m}$ \\
$f_{e}$ & Electromagnetic force of supporting unit [19] & $\mathrm{N}$ \\
$f_{h}$ & Hydrostatic force of supporting unit [20] & $\mathrm{m} / \mathrm{s}$ \\
$q_{0}$ & Flow of supporting cavity & Pa·s \\
$\mu$ & Dynamic viscosity of liquid & dimensionless \\
$B$ & Support flow coefficient & $\mathrm{m}^{2}$ \\
$A_{e}$ & Effective supporting area of supporting cavity & $\mathrm{m}$ \\
$A$ & Length and width of supporting cavity & $\mathrm{m}$ \\
$B$ & Length and width of supporting cavity & $\mathrm{m}$ \\
$a$ & Width of sealing belt & $\mathrm{m}$ \\
\hline
\end{tabular}

According to Equation (1), the kinetic equation of the single-DOF supporting system of MLDSB can be established.

$\left\{\begin{array}{l}\dot{x}=y \\ \dot{y}=-\sum_{i=1}^{2} \frac{\frac{\delta_{1} y}{m}}{\left[1+(-1)^{i+1} \frac{x}{h_{0}} \cos \theta\right]}+\frac{f_{h}}{m} \sum_{i=1}^{2} \frac{1+(-1)^{i} \frac{(A-2 a)(B-2 b)}{q_{0}} \cos \theta}{\left[1+(-1)^{i+1} \frac{x}{h_{0}} \cos \theta\right]^{3}}-\frac{f_{e}}{m} \sum_{i=1}^{2} \frac{\left[1+(-1)^{i} \frac{150}{i_{0}}\left(K_{p} x+K_{d}\right)\right]^{2}}{\left[1+(-1)^{i+1} \frac{x}{h_{0}} \cos \theta\right]^{2}}\end{array}\right.$

where $\delta_{1}=2 \mu A_{e} A_{b} \cos ^{2} \theta / \bar{B} h_{0}^{3}$.

\section{Static Bifurcation of the Single-DOF Supporting System}

Design parameters of MLDSB can be shown in Table 2. 
Table 2. Design parameters of MLDSB.

\begin{tabular}{cccc}
\hline Parameter & Name & Number & Unit \\
\hline$A$ & Length of Supporting cavity & 0.1 & $\mathrm{~m}$ \\
\hline$B$ & Width of Supporting cavity & 0.02 & $\mathrm{~m}$ \\
\hline$a$ & Width of sealing belt & 0.006 & $\mathrm{~m}$ \\
\hline$b$ & Width of sealing belt & 0.004 & $\mathrm{~m}$ \\
\hline$i_{0}$ & Initial Current & 1.2 & $\mathrm{Aa} \cdot \mathrm{s}$ \\
\hline$\mu$ & Dynamic viscosity & $1.3077 \times 10^{-3}$ & $\mathrm{~kg}$ \\
\hline$m$ & Mass of Rotor & 100 & $\mathrm{H} / \mathrm{m}$ \\
\hline$\mu_{0}$ & Permeability of air & $4 \pi \times 10^{-7}$ & $\mathrm{~mm}{ }^{2}$ \\
\hline$A_{e}$ & Supporting area & 1504 & $\mathrm{~mm}{ }^{2}$ \\
\hline$A_{b}$ & Extrusion area & 1056 & $\mu \mathrm{m}^{\circ}$ \\
\hline$h_{0}$ & Liquid film thickness & 30 & $\mathrm{dimensionless}^{2}$ \\
\hline$\theta$ & Angle & 22.5 & $\mathrm{~m}^{3} / \mathrm{s}$ \\
\hline$N$ & Number of turns & 60 & $\mathrm{dimensionless}$ \\
\hline$q$ & Flow of cavity & 3.2622 & $\mathrm{~mm}^{2}$ \\
\hline$A_{1}$ & Flow coefficient & 4.3611 &
\end{tabular}

According to the definition of singular point [21-23], the existence condition of singular point is that Equation (2) equals zero. The data in Table 1 is plugged into Equation (2), and coordinates of a singular point can be obtained as follows:

$$
\begin{gathered}
\left\{\begin{array}{l}
x_{0}=0 \\
y_{0}=0
\end{array}\right. \\
\left\{\begin{array}{l}
x_{1}= \pm \sqrt{\frac{-5.3795 \times 10^{-28}(\alpha-\beta)}{3 K_{p}^{2}+736 K_{p}}} \\
y_{1}=0
\end{array}\right. \\
\left\{\begin{array}{l}
x_{2}= \pm \sqrt{\frac{-5.3795 \times 10^{-28}(\alpha+\beta)}{3 K_{p}^{2}+736 K_{p}}} \\
y_{2}=0
\end{array}\right.
\end{gathered}
$$

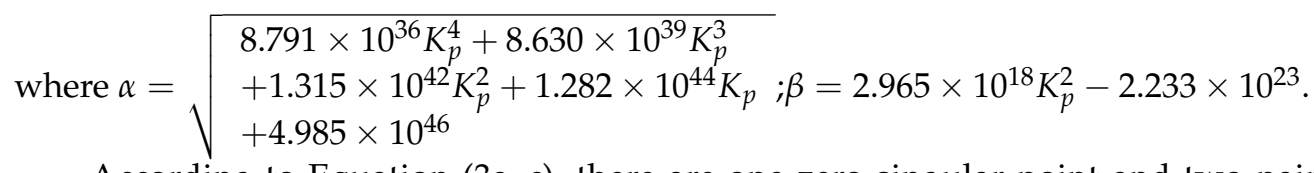

According to Equation $(3 a-c)$, there are one zero singular point and two pairs of nonzero singular points in the system. Coordinates of the singular point and static bifurcation are only related with coefficient $K_{p}$.

The curve of the abscissa xs of rotor's singular point and coefficient $K_{p}$ can be obtained by Matlab software, as shown in.

According to Figure 6, it can be demonstrated that nonzero singular points $\left(\mathrm{x}_{1,1}, 0\right)$, $\left(\mathrm{x}_{1,2}, 0\right)$ are beyond the range of film thickness, thus they are meaningless and can be ignored. There is one zero singular point $\left(\mathrm{x}_{0}, 0\right)$ when $K_{p}<-60.55$, while there are one zero singular point $\left(\mathrm{x}_{0}, 0\right)$ and two nonzero singular points $\left(\mathrm{x}_{2,1}, 0\right),\left(\mathrm{x}_{2,2}, 0\right)$ when $K_{p}>-60.55$. 


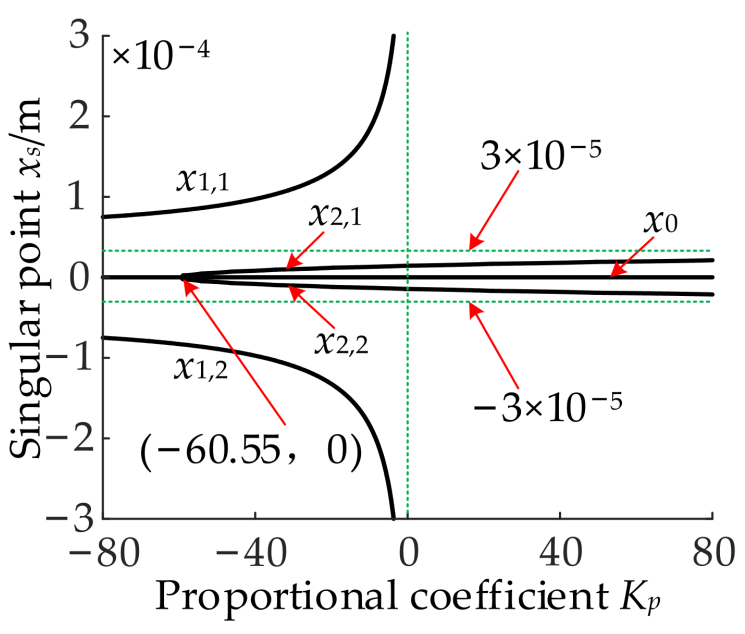

Figure 6. Static bifurcation of the single-DOF system.

In order to explore the change rule of singularity property under $K_{p}$ influence supporting system. Equation (2) can be expressed as follows:

$$
\left\{\begin{array}{l}
P(x, \dot{x})=\dot{x} \\
Q(x, \dot{x})=\dot{y}
\end{array}\right.
$$

The Jacobian Matrix on variable $x$ and can be established:

$$
A=\left(\begin{array}{ll}
\frac{\partial P}{\partial x} & \frac{\partial P}{\partial y} \\
\frac{\partial Q}{\partial x} & \frac{\partial Q}{\partial y}
\end{array}\right)=\left(\begin{array}{cc}
0 & 1 \\
\frac{\partial Q}{\partial x} & \frac{\partial Q}{\partial y}
\end{array}\right)
$$

The type of singular point depends on the roots of the characteristic equation of matrix $A$ [24]. The eigen equation of matrix $A$ is expanded as follows:

$$
\left|A_{1}-\lambda E\right|=\lambda^{2}-p \lambda+q=0
$$

where $p=\frac{\partial Q}{\partial y}, q=-\frac{\partial Q}{\partial x} E=\left(\begin{array}{ll}1 & 0 \\ 0 & 1\end{array}\right)$.

The range of parameter $K_{p}$ is $(-80,80)$.

(1) Characteristic of singular point $\left(\mathrm{x}_{0}, 0\right)$

The coordinates of the zero singular point are plugged into Equations (5) and (6):

$$
\left\{\begin{array}{l}
p=-1.595 \times 10^{3} \\
q=-1.664 \times 10^{4} K_{p}-1.008 \times 10^{6} \\
\Delta=p^{2}-4 q=6.656 \times 10^{4} K_{p}+6.576 \times 10^{6}
\end{array}\right.
$$

When $-80<K_{p}<-60.55, p<0, q>0, \Delta>0$, singular point $\left(\mathrm{x}_{0}, 0\right)$ is a stable node [25]. When $-60.55<K_{p}<80, p<0, q<0, \Delta>0$, singular point $\left(\mathrm{x}_{0}, 0\right)$ is a saddle.

(2) Characteristic of singular point $\left(\mathrm{x}_{2,1}, 0\right)$ and $\left(\mathrm{x}_{2,2}, 0\right)$

Nonzero singular points $\left(x_{2,1}, 0\right)$ and $\left(x_{2,2}, 0\right)$ exist in pairs, so it is possible to only analyze the characteristics of the nonzero singular point $\left(\mathrm{x}_{2,1}, 0\right)$. The existence condition of singular point $\left(x_{2,1}, 0\right)$ is $K_{p}>-60.55$, so the range of $K_{p}$ is $(-60.55,80)$. The coordinates of singular point $\left(x_{2,1}, 0\right)$ is plugged into Equations (5) and (6), and then the characteristic can be obtained:

When $-60.55<K_{p}<-27.14, p<0, q>0, \Delta>0$, singular point $\left(\mathrm{x}_{2,1}, 0\right)$ is a stable node. When $-27.14<K_{p}<35.18, p<0, q>0, \Delta<0$, singular point $\left(\mathrm{x}_{2,1}, 0\right)$ is a stable focus. When $35.18<K_{p}<80.00, p<0, q>0, \Delta>0$, singular point $\left(\mathrm{x}_{2,1}, 0\right)$ is a stable node. 


\section{Simulation and Experiment of the Single-DOF Supporting System}

\subsection{Phase Trajectories and Suction Basin of the Single-DOF Supporting System}

In order to analyze the phase trajectories characteristic of the single-DOF supporting system, four initial conditions are selected as follows:

$$
\left\{\begin{aligned}
\left(x_{1,0}, y_{1,0}\right) & =\left(-1.5 \times 10^{-5},-0.02\right) \\
\left(x_{2,0}, y_{2,0}\right) & =\left(-1.5 \times 10^{-5}, 0.02\right) \\
\left(x_{3,0}, y_{3,0}\right) & =\left(1.5 \times 10^{-5}, 0.02\right) \\
\left(x_{4,0}, y_{4,0}\right) & =\left(1.5 \times 10^{-5}, 0.02\right)
\end{aligned}\right.
$$

(1) Phase trajectories when $K_{p}=-70$

Setting $K_{p}=-70$, phase trajectories can be obtained by the fourth order Runge-Kutta method [26], as shown in Figure 7.

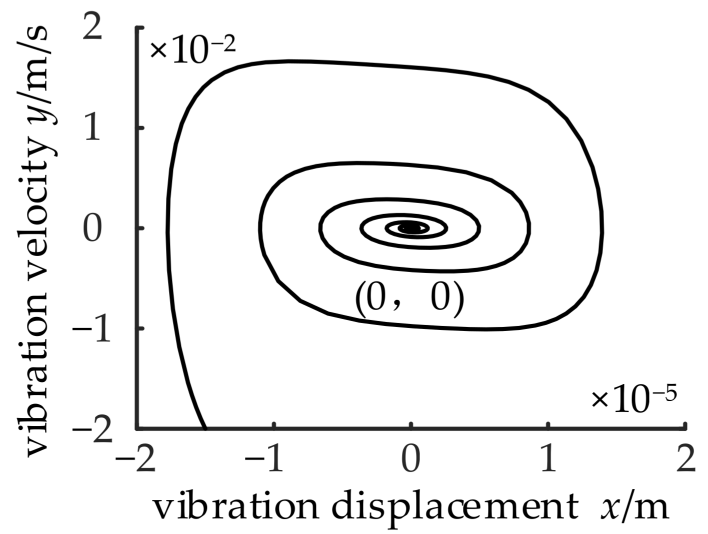

(a)

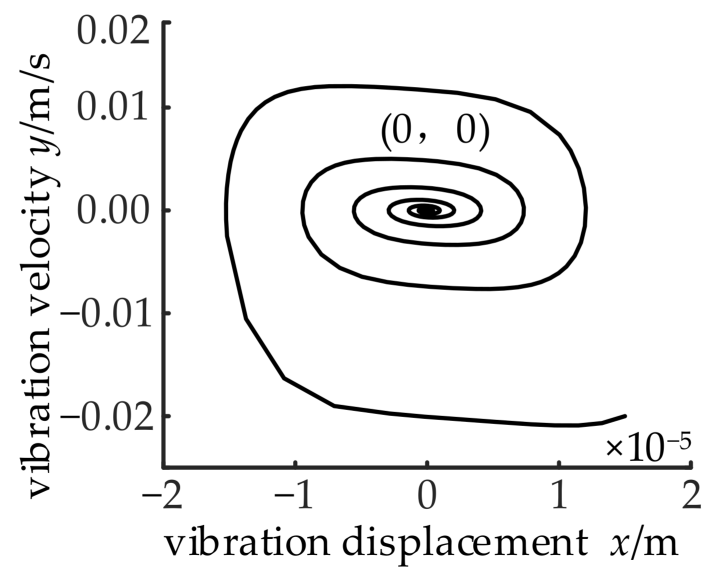

(c)

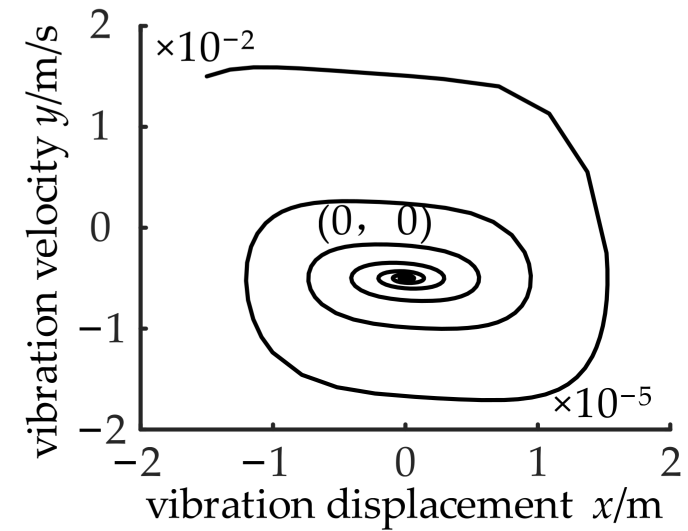

(b)

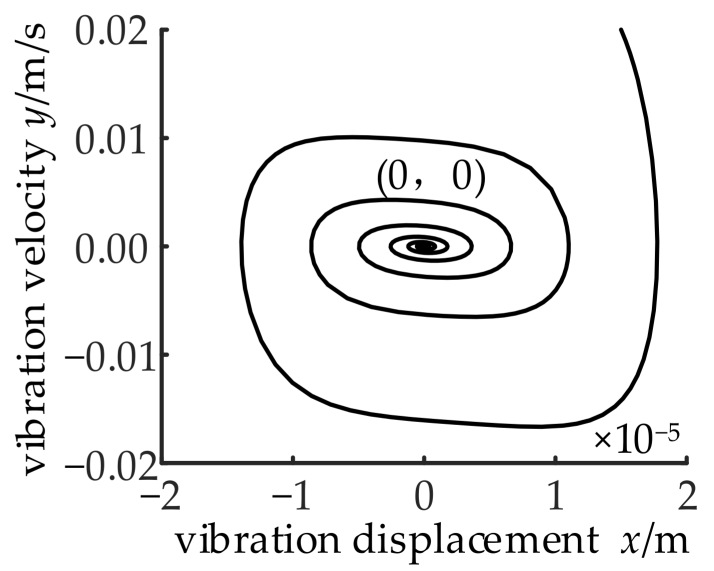

(d)

Figure 7. Phase trajectories when $K_{p}=-70$. (a) $\left(-1.5 \times 10^{-5},-0.02\right)$. (b) $\left(-1.5 \times 10^{-5}, 0.02\right)$. (c) $\left(1.5 \times 10^{-5},-0.02\right)$. (d) $\left(1.5 \times 10^{-5}, 0.02\right)$.

From Figure 7 , there is only one stable node $(0,0)$ in the supporting system when $K_{p}=-70$, phase trajectories of the rotor at different initial positions surround and gradually approach the node along the clockwise.

The appearances show that the supporting system in this state can achieve the stable support statement at the desired position after a period of adjustment, and then the operation stability of MLDSB can be guaranteed.

(2) Phase trajectories when $K_{p}=-30$

Setting $K_{p}=-30$, phase trajectories can be obtained, as shown in Figure 8. 


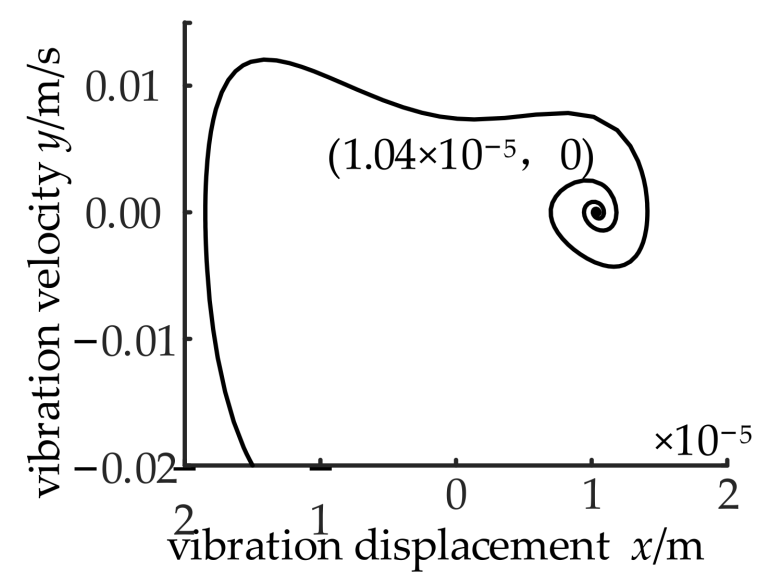

(a)

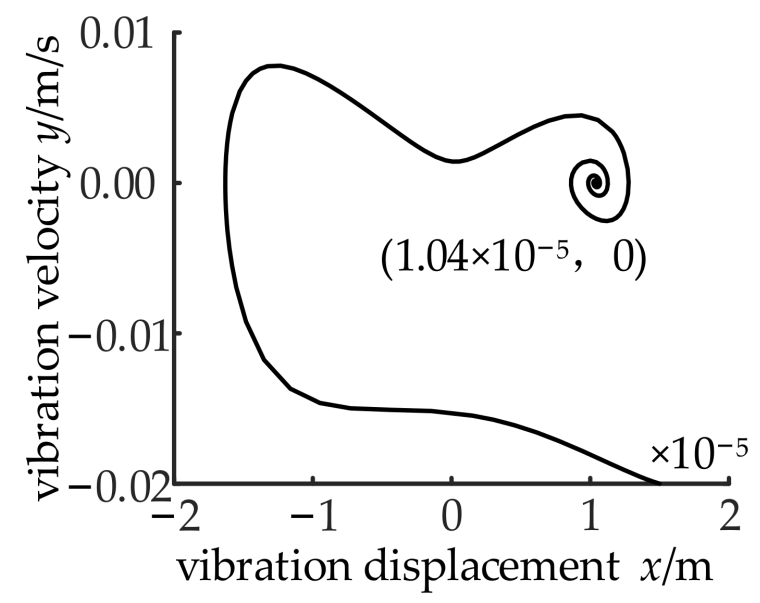

(c)

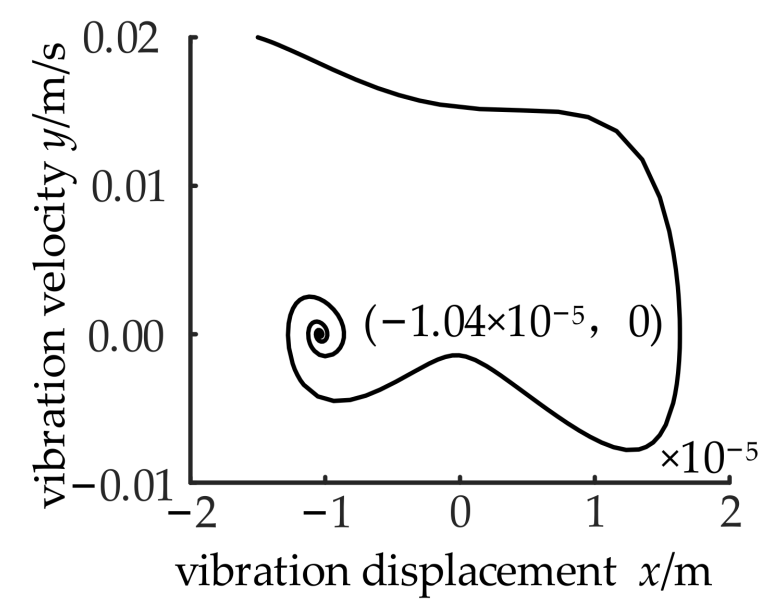

(b)

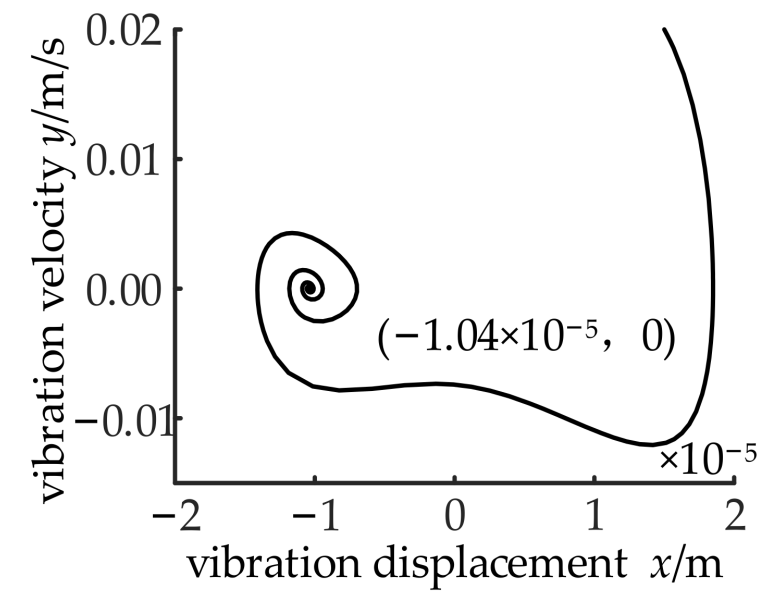

(d)

Figure 8. Phase trajectories when $K_{p}=-30$. (a) $\left(-1.5 \times 10^{-5},-0.02\right) .\left(\right.$ b) $\left(-1.5 \times 10^{-5}, 0.02\right) .(\mathbf{c})\left(1.5 \times 10^{-5},-0.02\right)$. (d) $\left(1.5 \times 10^{-5}, 0.02\right)$.

As shown in Figure 8, there is one unstable saddle $(0,0)$ and two stable nodes $\left(-1.04 \times 10^{-5}, 0\right),\left(-1.04 \times 10^{-5}, 0\right)$ when $K_{p}=-30$. Therefore, phase trajectories in Figure $8 \mathrm{a}, \mathrm{c}$ surround and approach the node $\left(1.04 \times 10^{-5}, 0\right)$ along the clockwise, while phase trajectories in Figure $8 b, d$ surround and approach the node $\left(-1.04 \times 10^{-5}, 0\right)$.

The appearances show that the supporting system in this state can remain balanced after adjustment. However, the equilibrium point is not the desired working positionthe rotation center of the bearing; therefore, the operation stability of MLDSB cannot be guaranteed.

(3) Phase trajectories when $K_{p}=30$

Setting $K_{p}=30$, phase trajectories can be obtained, as shown in Figure 9.

From Figure 9 , there is one unstable saddle $(0,0)$ and two stable focus $\left(-1.75 \times 10^{-5}\right.$, $0),\left(1.75 \times 10^{-5}, 0\right)$ when $K_{p}=30$. Therefore, phase trajectories in Figure 9a,b surround and approach the focus $\left(-1.75 \times 10^{-5}, 0\right)$ along the clockwise, while phase trajectories in Figure $9 \mathrm{c}$, d surround and approach the focus $\left(1.75 \times 10^{-5}, 0\right)$.

Similarly, although the supporting system in this state can keep balanced, the equilibrium point is not the desired working position-the rotation center of the bearing; therefore, the operation stability of MLDSB cannot be guaranteed. 


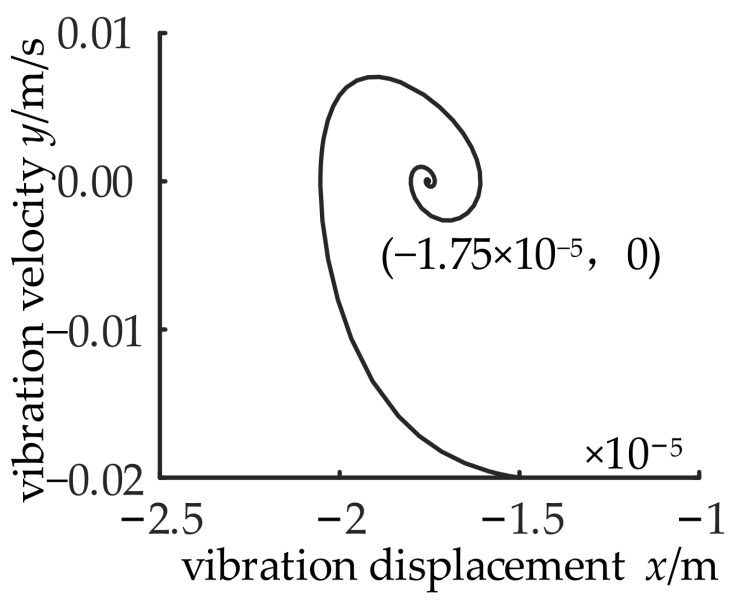

(a)

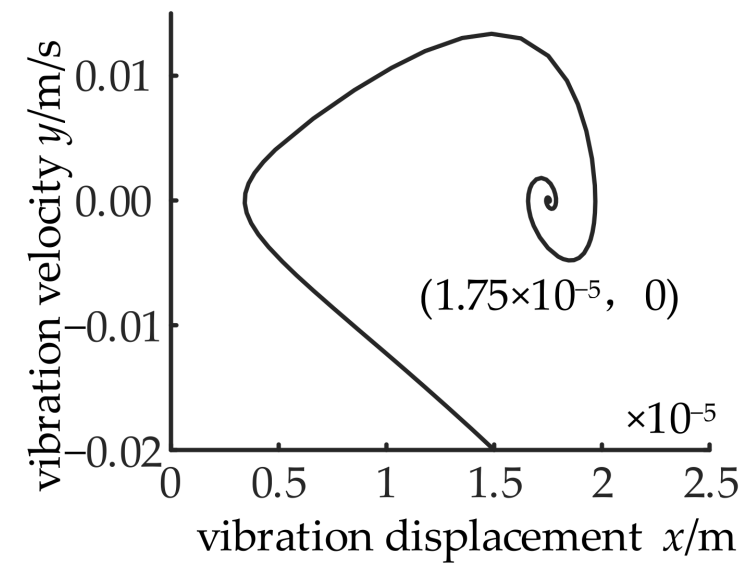

(c)

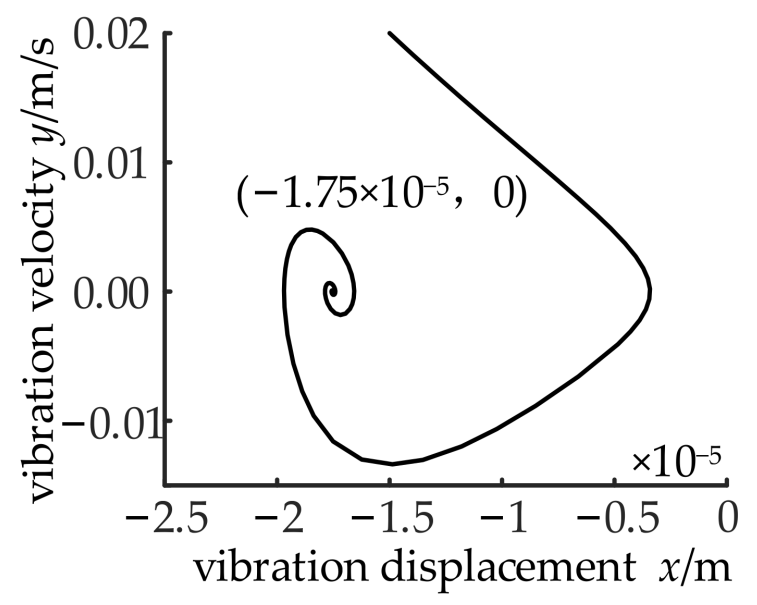

(b)

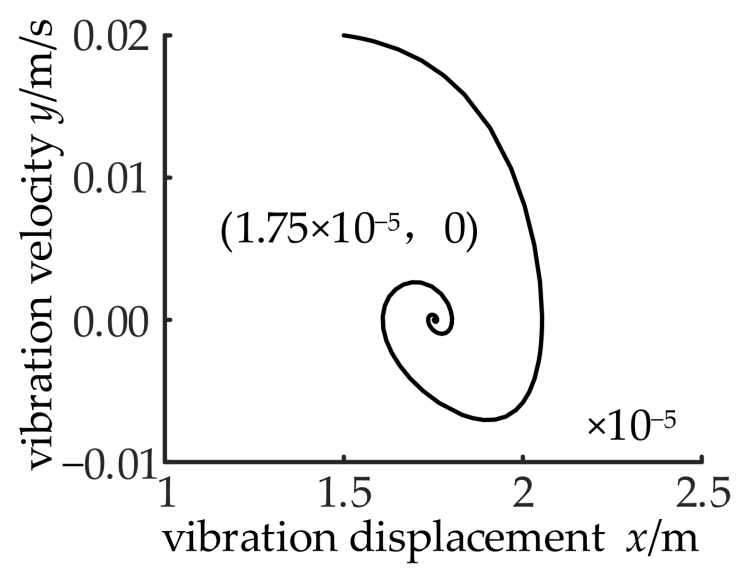

(d)

Figure 9. Phase trajectories when $K_{p}=30$. (a) $\left(-1.5 \times 10^{-5},-0.02\right)$. (b) $\left(-1.5 \times 10^{-5}, 0.02\right)$. (c) $\left(1.5 \times 10^{-5},-0.02\right)$. (d) $\left(1.5 \times 10^{-5}, 0.02\right)$.

(4) Phase trajectories when $K_{p}=70$

Setting $K_{p}=70$, phase trajectories can be obtained, as shown in Figure 10.

From Figure 10 , there is one unstable saddle $(0,0)$ and two stable nodes $\left(-2.07 \times 10^{-5}\right.$, $0),\left(2.07 \times 10^{-5}, 0\right)$ when $K_{p}=70$. Therefore, phase trajectories in Figure $10 \mathrm{a}, \mathrm{b}$ surround and approach the node $\left(-2.07 \times 10^{-5}, 0\right)$, while phase trajectories in Figure $10 \mathrm{c}$, d surround and approach the node $\left(2.07 \times 10^{-5}, 0\right)$.

Similarly, although the supporting system in this state can keep balanced, the equilibrium point is not the desired working position-the rotation center of the bearing, therefore, the operation stability of MLDSB cannot be guaranteed.

According to the phase trajectories of the supporting system, it can be shown that different singular points which correspond to different initial phase points will also change as the coefficient $K_{p}$ increases gradually, therefore, it is necessary to analyze basin of attraction of the single-DOF supporting system of MLDSB.

According to singular point and phase trajectories, it can be demonstrated that when $K_{p}<-60.55$, all phase points will eventually be attracted to the singular point $(0,0)$, thus it is not necessary to draw the basin of attraction.

When $K_{p}>-60.55$, as coefficient $K_{p}$ increases, the basin of attraction varies continuously, as shown in Figure 11. 


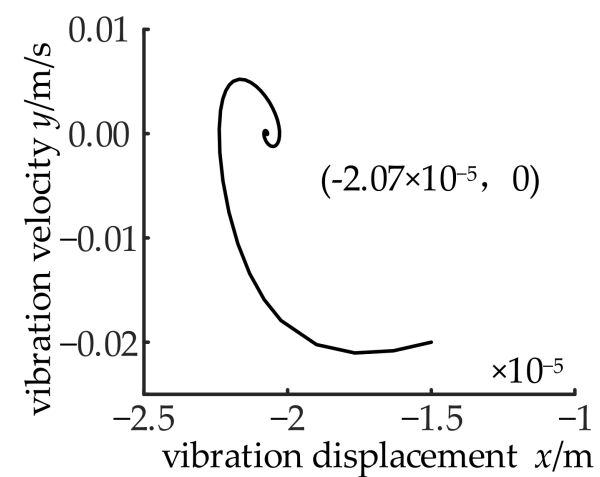

(a)

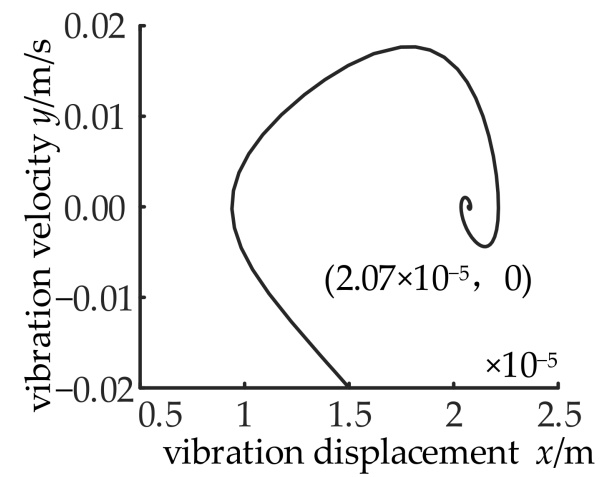

(c)

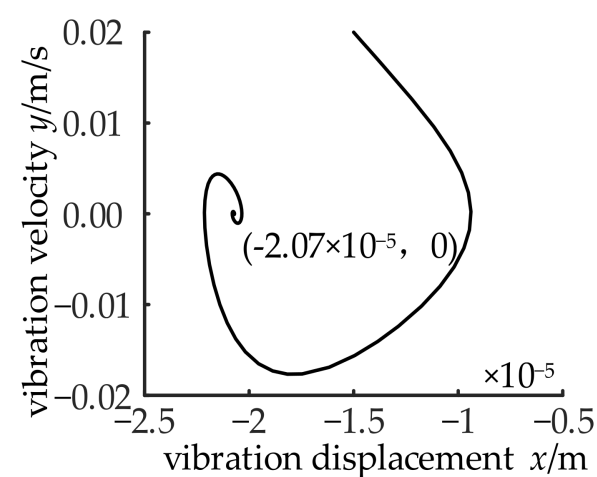

(b)

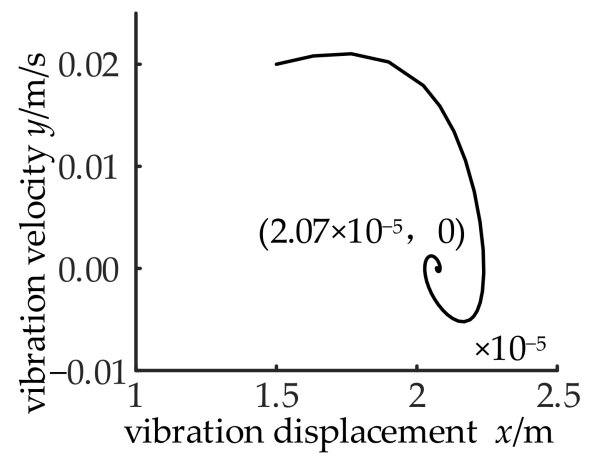

(d)

Figure 10. Phase trajectories when $K_{p}=70$. (a) $\left(-1.5 \times 10^{-5},-0.02\right)$. (b) $\left(-1.5 \times 10^{-5}, 0.02\right)$. (c) $\left(1.5 \times 10^{-5},-0.02\right)$. (d) $\left(1.5 \times 10^{-5}, 0.02\right)$.

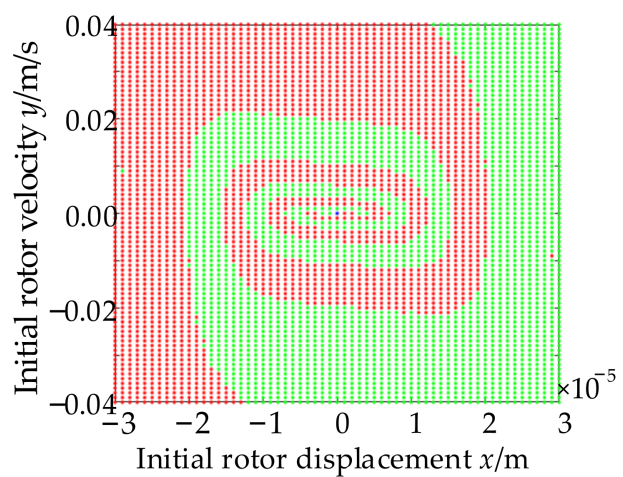

(a)

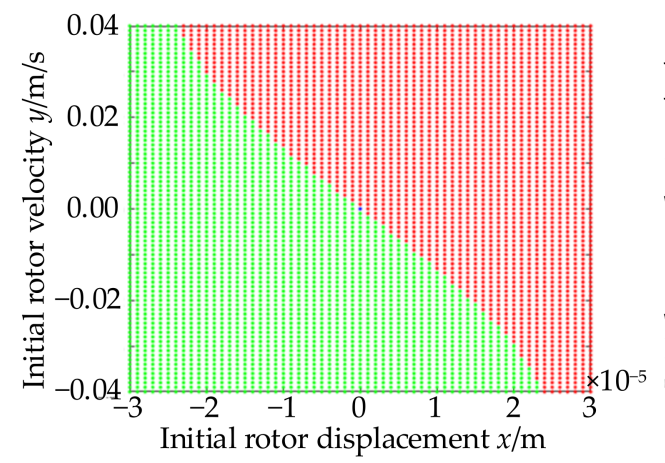

(c)

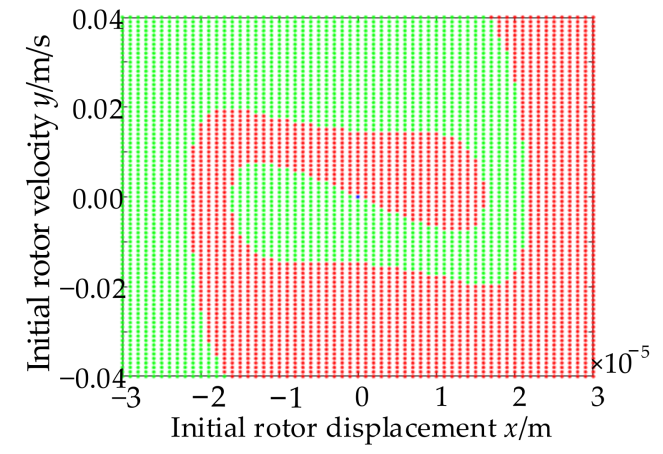

(b)

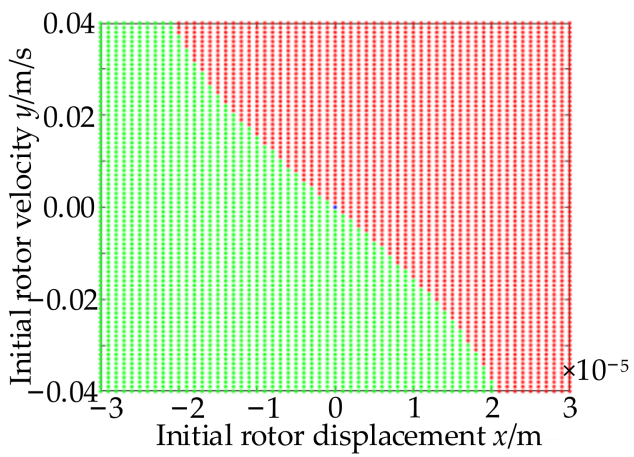

(d)

Figure 11. Photo of basin of attraction. (a) Basin of attraction when $K_{p}=-60$. (b) Basin of attraction when $K_{p}=-30$. (c) Basin of attraction when $K_{p}=30$. (d) Basin of attraction when $K_{p}=60$. 
Phase points in the red region of Figure 11 will eventually be attracted to the singular point $\left(x_{2,1}, 0\right)$, while phase points in the green region will be attracted to the singular point $\left(\mathrm{x}_{2,2}, 0\right)$.

From Figure 11, all the basin of attraction of the single DOF supporting system distributes symmetrically. When coefficient $K_{p}$ increases from -60.55 to 30 , the shape of the basin of attraction changed greatly and the final stable equilibrium point is more sensitive to coefficient $K_{p}$.

When the coefficient $K_{p}>30$, the shape of the basin of attraction changed slightly and the final stable equilibrium point is not sensitive to coefficient $K_{p}$.

\subsection{Experimental Result of Static Bifurcation}

4.2.1. Brief Introduction of the MLDSB Testing System

The testing system is composed of an electronic control system, a hydrostatic system and a bearing body, as shown in Figure 12.

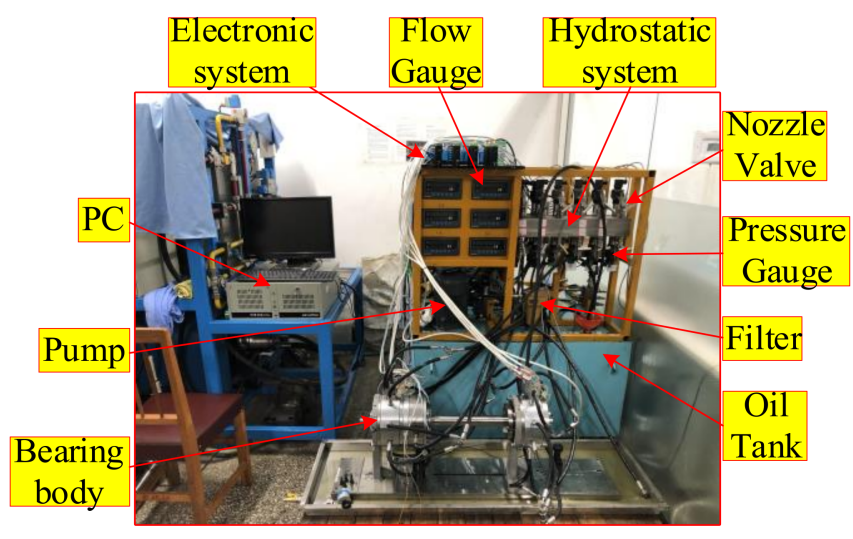

(a)

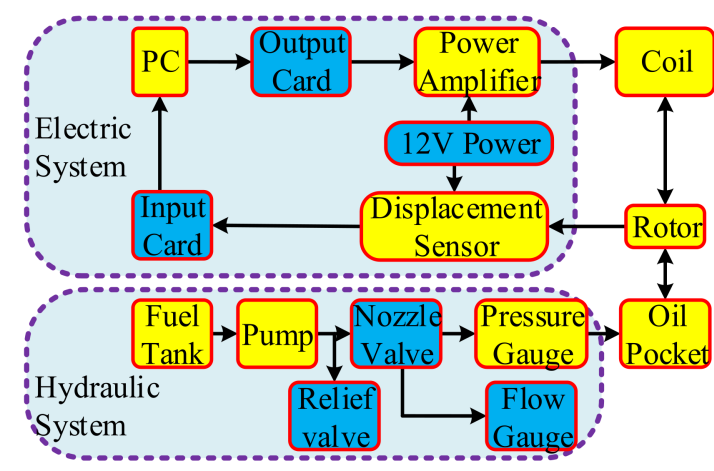

(b)

Figure 12. MLDSB Testing System. (a) Photo of MLDSB Testing System. (b) Connection diagram of MLDSB Testing System.

Hydrostatic system is a constant pressure supporting model, and its flow is adjusted by a needle valve. Electronic control system is a closed-loop position control system, and its current is adjusted by a PD controller. The principles of hydrostatic systems and electronic control systems are shown in Figure 4, the bearing body is shown in Figure 1 and the parameters of experimental device is shown in Table 3.

Table 3. Parameters of experimental device.

\begin{tabular}{cc}
\hline Element & Model \\
\hline Hydraulic pump & TGPVL4-200SH \\
\hline Relief valve & DBD-H-6-P-10-B-NG10 \\
\hline Nozzle valve & A7-2-KL2-0KL20-PTFE \\
\hline Flow gauge & LWGY-S \\
\hline Pressure gauge, & HSTL-802 \\
\hline Displacement gauge & VB-Z9900 \\
\hline Coil & Cu \\
\hline PC & IPC-610L \\
\hline Output card, & PCI1716 \\
\hline Input card & AQMD3620NS-A2 \\
\hline Power amplifier
\end{tabular}




\subsubsection{Experimental Procedure}

Experimental procedure of static bifurcation is shown as follows:

(1) Switch on the power and adjust the hydrostatic system to constant pressure supporting model.

(2) Adjust the opening of the needle valve to make sure that the rotor is stably suspended in the initial position.

(3) Switch on electronic control system and adjust parameter $K_{p}$.

(4) Adjust i0 to make sure that the rotor is stably re-suspended in the initial position.

(5) Strike the rotor by hammer to make it stably re-suspended in the equilibrium position.

(6) Collect the pressure of the oil pocket by pressure gauge, extract the current of the coil, and collect the displacement of the rotor by displacement sensor.

(7) Repeat steps (2) steps (6).

\subsubsection{Analysis of Experimental Result}

(1) Static bifurcation of stator when $K_{p}=30$

Set $K_{p}=30$, and then the displacement and phase trajectories of the rotor, the pressure of the oil pocket, and the current of the coil can be tested experimentally, as shown in Figures 13-16.

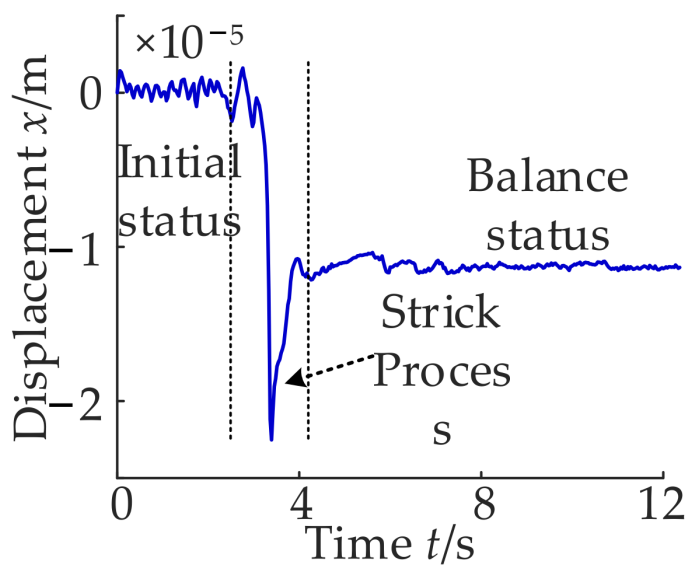

Figure 13. Displacement of rotor by test when $K_{p}=30$.

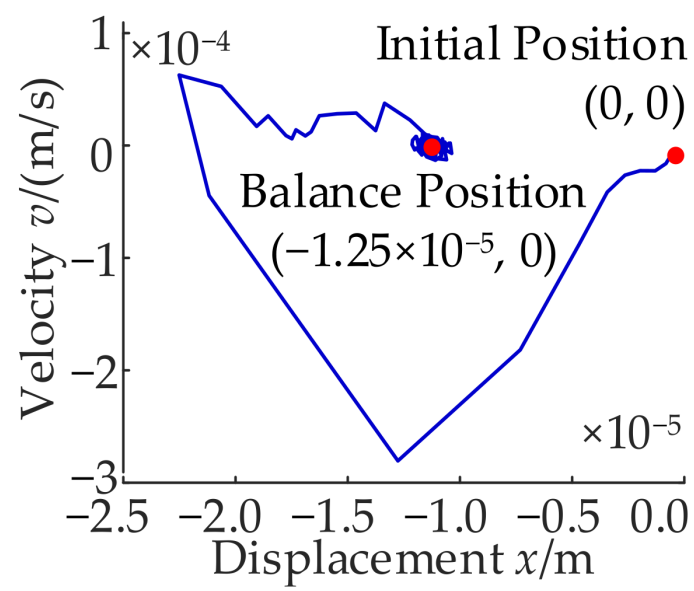

Figure 14. Phase trajectories of rotor by test when $K_{p}=30$. 


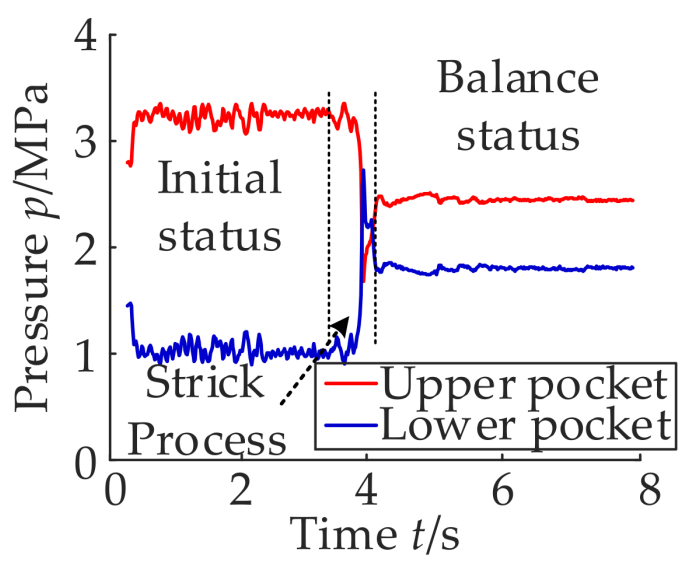

Figure 15. Oil pocket pressure by test when $K_{p}=30$.

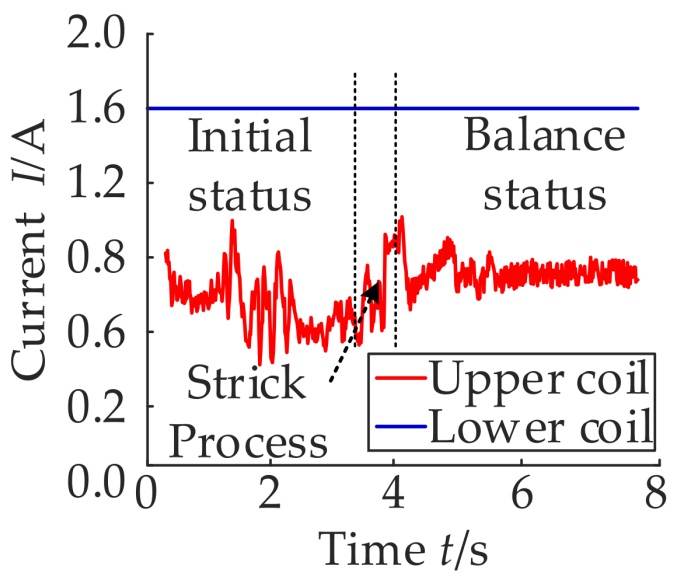

Figure 16. Current of coil by test when $K_{p}=30$.

By comparing Figures $9 \mathrm{~b}$ and 14, it can be observed that the phase trajectories of rotors obtained by theoretical simulation and experimental tests are basically the same. The phenomenon of static bifurcation occurs when it rotates clockwise from the initial point and gradually converges to the equilibrium point.

The equilibrium points of theoretical simulation and experimental tests are $\left(-1.75 \times 10^{-5}, 0\right)$ and $\left(-1.25 \times 10^{-5}, 0\right)$, respectively, and its error is $5 \mu \mathrm{m}$. This is due to the leakage and damping effect of the hydrostatic system, and it is within the allowable range of the engineering.

During the process of experimental testing, the rotor can only be stabilized at the initial balance position $(0,0)$, so it is different from the initial point $\left(-1.5 \times 10^{-5}, 0.02\right)$ of theoretical simulation, but the bifurcation behavior and law of the rotor are consistent.

From Figure 15, when the rotor moves from the initial position $(0,0)$ to the balance position $\left(-1.25 \times 10^{-5}, 0\right)$, the upper hydraulic resistance reduces and the lower hydraulic resistance increases, and then the upper pocket's pressure reduces from $3.2 \mathrm{MPa}$ to $2.3 \mathrm{MPa}$ and the lower pocket's pressure increases from $1 \mathrm{MPa}$ to $1.8 \mathrm{MPa}$.

Due to single coil adjustment in the electronic control system, the upper coil's current is shown in Figure 16, while the lower coil's current remains the same. After applying the external load, the rotor moves from the initial position $(0,0)$ to the balance position $\left(-1.25 \times 10^{-5}, 0\right)$, and the upper coil's current increases from $0.6 \mathrm{~A}$ to $0.8 \mathrm{~A}$ after the brief adjustment.

(2) Static bifurcation of stator when $K_{p}=-70$

Similarly, set $K_{p}=-70$, and then the displacement and phase trajectories of the rotor, the pressure of the oil pocket, and the current of the coil can be tested experimentally, as shown in Figures 17-19. 


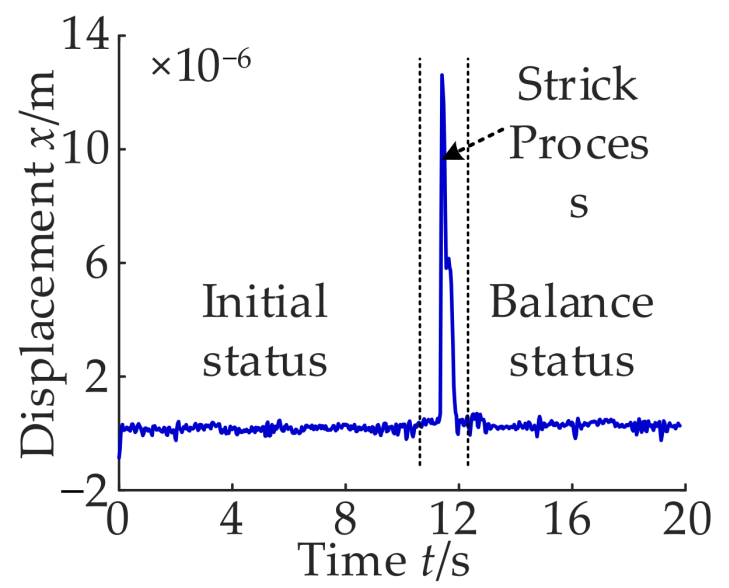

Figure 17. Displacement of rotor by test when $K_{p}=-70$.

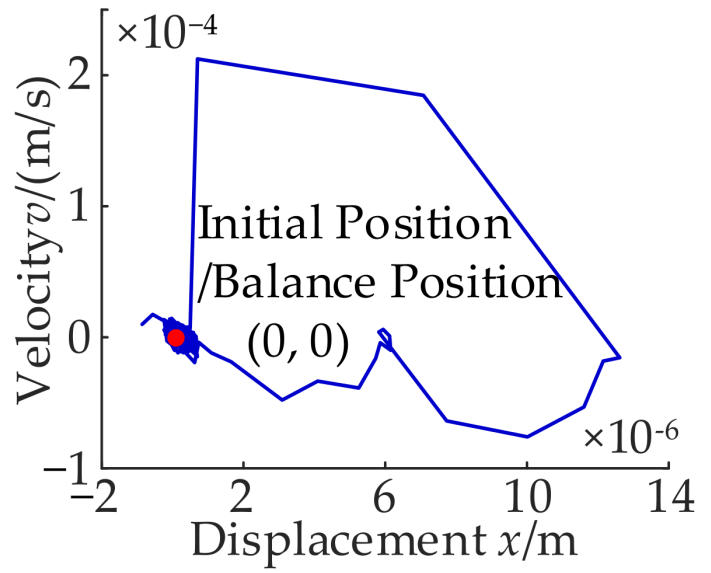

Figure 18. Phase trajectories of rotor by test when $K_{p}=-70$.

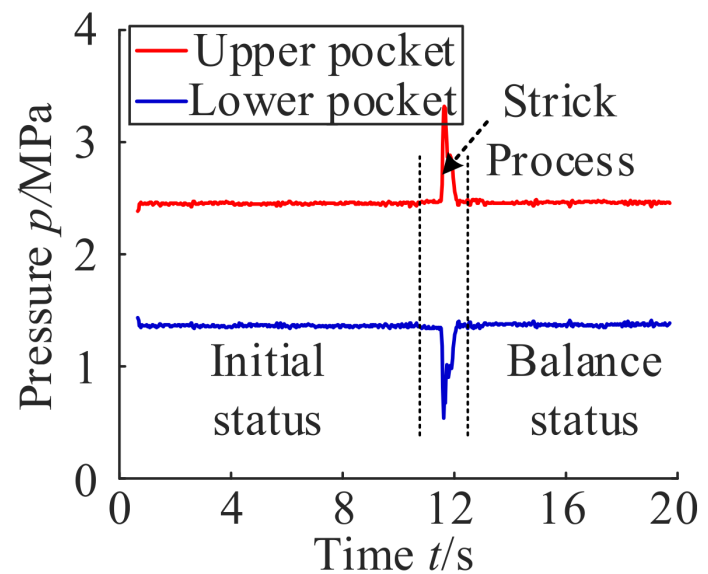

Figure 19. Oil pocket pressure by test when $K_{p}=-70$.

As the initial position and the balance position of the rotor are $(0,0)$, the film thickness and the pressure of the oil pocket remain the same after applying the external load, and the pressure of the upper pocket and the lower pocket are $2.40 \mathrm{MPa}$ and $1.35 \mathrm{MPa}$, respectively, as shown in Figure 20. 


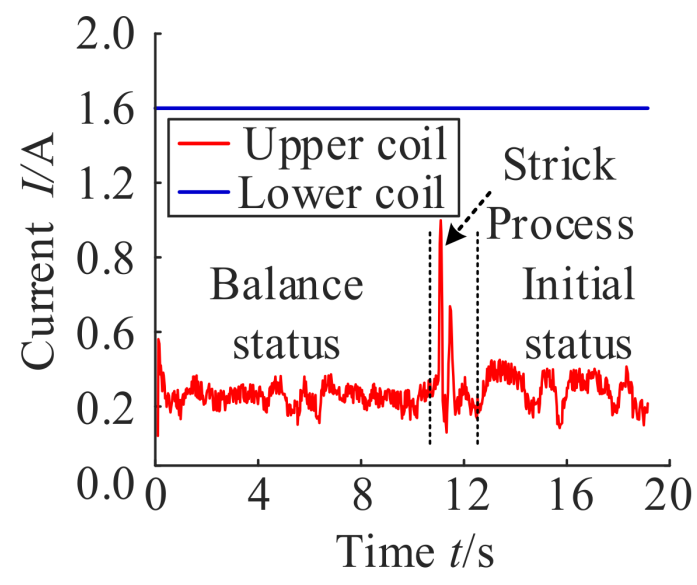

Figure 20. Current of coil by test when $K_{p}=-70$.

Similarly, the current of the upper coil and the lower coil remain the same, and they are $0.2 \mathrm{~A}$ and $1.6 \mathrm{~A}$, respectively.

In order to ensure the contrast of test results, phase trajectory at $K_{p}=-70$ is obtained using a theoretical analysis method in the paper, as shown in Figure 21.

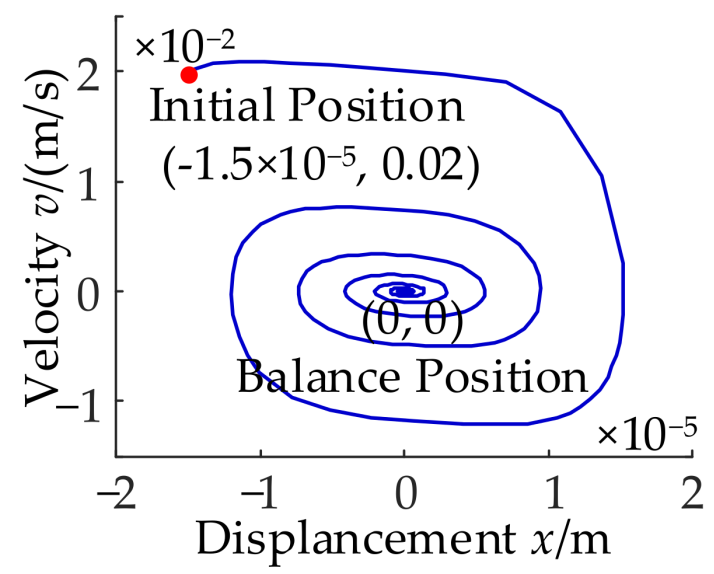

Figure 21. Phase trajectories by simulation when $K_{p}=-70$.

By comparing Figure 18 with Figure 21, it can be demonstrated that the rotor phase trajectory obtained from theoretical simulation and experimental tests are basically consistent, and it rotates clockwise from the initial point and gradually converges to the equilibrium point $(0,0)$ without static bifurcation.

Similarly, the initial point position of the rotor in the experimental test is $(0,0)$, which is somewhat different from the initial point position $\left(-1.5 \times 10^{-5}, 0.02\right)$ in the theoretical simulation, but the bifurcation behavior of the rotor and its law are consistent.

\section{Conclusions}

(1) The boundary value and the number of singularities of static bifurcation of the bearing system under the influence of the controller parameter $K_{p}$ are calculated and solved. When $K_{p}<-60.55$, there are zero singularities $\left(\mathrm{x}_{0}, 0\right)$ in the system, and no static bifurcation occurs, the bearing rotor will run stably at that point. When $K_{p}>-60.55$, the supporting system has one zero singularities $\left(\mathrm{x}_{0}, 0\right)$ and two non-zero singularities $\left(\mathrm{x}_{2,1}, 0\right),\left(\mathrm{x}_{2,2}, 0\right)$, and static bifurcation occurs. When $K_{p}=-60.55$, the pitchfork bifurcation will occur.

(2) The change law of zero and non-zero singularities under the influence of the controller parameter $K_{p}$ is explored. For zero singularities, when $-80<K_{p}<-60.55$, zero 
singularities are the stable focus, the bearing rotor will run stably at that point. When $-60.55<K_{p}<80$, the zero singularity is the saddle point, the bearing rotor will appear in two states of stable operation and instability in a movement cycle. For the non-zero singularity, when $-60.55<K_{p}<-27.14$, the singularity is the stable node, the bearing rotor will run stably at that point. When $-27.14<K_{p}<35.18$, the singularity is the stable focus, the bearing rotor will run stably at that point. When $35.18<K_{p}<80$, the singularity is the stable node, the bearing rotor will run stably at that point.

(3) Conclusions (1) and (2) are verified by theoretical simulation and experiment.

\begin{abstract}
Author Contributions: Conceptualization, J.Z. and H.Z.; methodology, H.Z.; software, H.Z.; validation, J.Z., H.Z., Y.W. and B.Q.; formal analysis, X.W.; investigation, F.H.; resources, F.H.; data curation, G.D.; writing—original draft preparation, G.D.; writing—review and editing, J.Z.; visualization, H.Z.; supervision, J.Z.; project administration, H.Z.; funding acquisition, J.Z. All authors have read and agreed to the published version of the manuscript.
\end{abstract}

Funding: This research was funded by the National Natural Science Foundation of China (No. 52075468), General project of Natural Science Foundation of Hebei Province (No. E2020203052), Youth Fund Project of scientific research project of Hebei University (No. QN202013) and Open Project Funding of Fluid Power Transmission Control Laboratory of Yanshan University.

Institutional Review Board Statement: Not applicable.

Informed Consent Statement: Informed consent was obtained from all subjects involved in the study.

Data Availability Statement: Not applicable.

Conflicts of Interest: The authors declare no conflict of interest.

\title{
References
}

1. Chen, R.; Li, H.W.; Tian, J. The Relationship between the Number of Magnetic Poles and the Bearing Capacity of Radial Magnetic Bearing. J. Shandong Univ. 2018, 48, 81-85, 93.

2. Zhao, J.H.; Yan, W.D.; Wang, Z.Q. Study on Clearance-Rubbing Dynamic Behavior of 2-DOF Supporting System of MagneticLiquid Double Suspension Bearing. Processes 2020, 8, 973-987. [CrossRef]

3. Lou, Y.B.; Zhang, X.Y.; Fang, X. Research on Multi-Factor Coupling of Radial Magnetic Bearings. Bearing 2018, 1, $18-23$.

4. He, Q.X.; Zhao, T.F.; Cao, S.H.; Sun, N. Influence of Controller Parameters on Control Characteristics of a Magnetic Bearings System. Mech. Sci. Technol. 2006, 25, 530-533.

5. Chen, J.; Lv, B.J.; Peng, L.K.; Song, F. Research on two-parameter Hopf Bifurcation of digital hydraulic actuator system. J. Nav. Univ. Eng. 2021, 33, 65-70.

6. Yang, S.Y.; Li, J.H.; Wu, H.T.; Chen, Z. The Nonlinear of the AMBs Influenced by the Controller's Parameters. Chin. J. Sci. Instrum. 2005, 26, 1732-1734.

7. Ji, J.C.; Hansen, C.H.; Zander, A.C. Nonlinear Dynamics of Magnetic Bearing Systems. J. Intell. Mater. Syst. Struct. 2008, 19, 1471-1491. [CrossRef]

8. Ji, J.C.; Leung, A.Y.T. Nonlinear oscillations of a rotor-magnetic bearing system under super-harmonic resonance conditions. Int. J. Non-Linear Mech. 2003, 38, 829-835. [CrossRef]

9. Ji, J.C.; Leung, A.Y.T. Resonances of a nonlinear SDOF system with two time-delays in linear feedback control. J. Sound Vib. 2002, 253, 985-1000. [CrossRef]

10. Chen, X.H.; Ma, W.H. Analysis on the Effect of Controller Time Delay on the Stability of Maglev System. Electr. Drive Locomot. 2019, 2, 139-143, 147.

11. Ji, J.C. Stability and bifurcation in an electromechanical system with time delays. Mech. Res. Commun. 2003, 30, 217-225. [CrossRef]

12. Ji, J.C.; Leung, A.Y.T. Bifurcation control of a parametrically excited Duffing system. Nonlinear Dyn. 2002, 27, 411-417. [CrossRef]

13. Ji, J.C.; Hansen, C.H. Local bifurcation control in a rotor-magnetic bearing system. Int. J. Bifurc. Chaos 2003, 13, 951-956. [CrossRef]

14. Li, L.; Shi, F.B.; Zhang, Q.Z. Development of the Digital Speed-Controlling Unit for Electric Running-Rigs. J. Xi'an Shiyou Univ. 2006, 21, 91-93.

15. Lan, H.W. Stability and bifurcation of periodic motions and the permanent magnet rotor system with rubbing. J. Mech. Strength 2017, 39, 267-272.

16. Zhao, J.H.; Zhou, S.L.; Lu, X.H.; Gao, D. Numerical Simulation and Experimental Study of Heat-Fluid-Solid Coupling of Double Flapper-Nozzle Servo Valve. Chin. J. Mech. Eng. 2018, 28, 1030-1038. [CrossRef]

17. Reza, E.; Mostafa, G.; Mohammad, K.H. Nonlinear Dynamic Analysis and Experimental Verification of a Magnetically Supported Flexible Rotor System with Auxiliary Bearings. Mech. Mach. Theory 2018, 1, 545-562. 
18. Zhao, J.H.; Chen, T.; Wang, Q.; Zhang, B.; Gao, D.-R. Stability Analysis of Single DOF Support System of Magnetic-Liquid Double Suspension Bearing. Hydromechatronics Eng. 2019, 47, 1-7.

19. Weiss, G.; Staffans, O.J. Maxwell's Equations as a Scattering Passive Linear System. SIAM J. Control Optim. 2013, 51, 3722-3756. [CrossRef]

20. Sudeep, V.; Anupam, D. Partially-Averaged Navier-Stokes (PANS) Approach for Study of Fluid Flow and Heat Transfer Characteristics in Czochralski Melt. J. Cryst. Growth 2018, 481, 56-64.

21. Hu, L.; Zong, M. Research on Semi-physical Simulation of Electromagnetic Bearing Control System Based on Dspace. Micricontrollers Embed. Syst. 2016, 16, 61-64.

22. Yang, J.; Li, X.M. States Feedback Control of Single-degree-freedom Magnetism Suspension System. Comput. Meas. Control 2005, $13, \mathrm{v} 472-\mathrm{v} 473$.

23. Liu, Y.Z.; Chen, L.Q. Nonlinear Vibrations; Higher Education Press: Beijing, China, 2001.

24. Zhang, Q.C.; Wang, H.L.; Zhu, Z.W.; Shen, F.; Ren, A.D.; Liu, H.Y. Theory and Application of Bifurcation and Chaos; Tianjin University Press: Tianjin, China, 2005.

25. Chen, Y.S. Nonlinear Vibrations; Tianjin Science and Technology Press: Tianjin, China, 1983.

26. Luo, H.Y.; Wang, Y.F.; Wu, C.W. Nonlinear vibration and bifurcation of continuous rotor bearing systems excited by electromagnetic force. Chin. J. Appl. Mech. 2011, 28, 675. 